\title{
Genetic diversity of the movement and coat protein genes of South American isolates of Prunus necrotic ringspot virus
}

\author{
Nicola Fiore · Thor V. M. Fajardo · Simona Prodan · María Carmen Herranz • \\ Frederic Aparicio - Jaime Montealegre - Santiago F. Elena · Vicente Pallás · \\ Jesús Sánchez-Navarro
}

Received: 29 October 2007 / Accepted: 14 February 2008/Published online: 26 March 2008

(C) Springer-Verlag 2008

\begin{abstract}
Prunus necrotic ringspot virus (PNRSV) is distributed worldwide, but no molecular data have been previously reported from South American isolates. The nucleotide sequences corresponding to the movement (MP) and coat (CP) proteins of 23 isolates of PNRSV from Chile, Brazil, and Uruguay, and from different Prunus species, have been obtained. Phylogenetic analysis performed with full-length MP and CP sequences from all the PNRSV isolates confirmed the clustering of the isolates into the previously reported PV32-I, PV96-II and PE5-III phylogroups. No association was found between specific sequences and host, geographic origin or symptomatology. Comparative analysis showed that both MP and CP have phylogroup-specific amino acids and all of the motifs previously characterized for both proteins. The study of the distribution of synonymous and nonsynonymous changes along both open reading frames revealed that most amino acid sites are under the effect of negative purifying selection.
\end{abstract}

N. Fiore $\cdot$ S. Prodan $\cdot$ J. Montealegre

Facultad de Ciencias Agronómicas, Universidad de Chile,

Avenida Santa Rosa, 11315 Santiago, Chile

M. C. Herranz · F. Aparicio · S. F. Elena - V. Pallás .

J. Sánchez-Navarro $(\bowtie)$

Instituto de Biología Molecular y Celular de Plantas, Consejo Superior de Investigaciones Científicas-UPV, CPI 8E, C/ Ingeniero Fausto Elio s/n, 46022 València, Spain e-mail: jesanche@ibmcp.upv.es

T. V. M. Fajardo

Embrapa Uva e Vinho, Rua Livramento, 515,

Bento Gonçalves, RS CEP: 95.700-000, Brazil

\section{Introduction}

The South American production of stone fruit trees represents $6.3 \%$ of the world fruit production (FAO 2005). Stone fruit trees are affected by a large number of viruses, which cause significant economic losses [38]. Among these many viruses, the most economically important ilarvirus is Prunus necrotic ringspot virus (PNRSV). PNRSV has a worldwide distribution and affects Prunus spp. including commercial peach, nectarine, cherry, apricot, almond and plum trees [19, 37]. The typical symptoms induced by PNRSV are chlorosis, necrosis, leaf deformation, and growth defects. Chlorosis usually forms rings, bands, lines, mottles, mosaics and arabesques. Ring necrosis mainly affects leaves but also appears on branches and emerging buds in the case of aggressive strains. The foliar rings, initially chlorotic, become necrotic and drop off, resulting in perforations of the leaf $[13,37,47]$. PNRSV is transmitted by pollen, seed and routine vegetative propagation methods [6, 12, 20, 21, 30].

PNRSV belongs to the genus Ilarvirus of the family Bromoviridae, and its genome is organized into three plusstrand RNAs. RNAs 1 and 2 encode for proteins involved in viral replication, whereas RNA 3 encodes a $5^{\prime}$-proximal movement protein (MP) and a $3^{\prime}$-proximal coat protein (CP), which is expressed via a subgenomic RNA 4 [9]. Many different isolates of PNRSV have been characterized and phylogentically grouped into three subgroups named PV32-I, PV96-II and PE5-III [3, 4, 13, 22, 46, 48]. Analysis of the different isolates revealed a lack of association between specific nucleotide or amino acids patterns and the host origin, symptomatology or geographic area. Nonetheless, the majority of isolates from phylogroups PV96-II and PV32-I tend to exhibit latent/mild or chlorotic/necrotic symptoms, respectively [4, 22, 23]. Molecular analyses of 
the coding sequences of $\mathrm{CP}$ and MP revealed that both proteins are highly conserved despite the host and geographical origin of the isolates being compared [3]. The PNRSV MP has been assigned to the $30 \mathrm{~K}$ superfamily, a group of twenty genera the MPs of which are related to the MP of tobacco mosaic virus (TMV) [36]. Analyses performed with the MP of PNRSV and the closely related alfalfa mosaic virus (AMV) have allowed characterization of an RNA-binding domain upstream of the transmembrane motif $[26,27,45]$, the region responsible for tubule formation [41] and the C-terminal portion of the protein that specifically interacts with the cognate CP [40]. Two different motifs have been characterized for the $\mathrm{CP}$ genes of both PNRSV and AMV: an RNA-binding domain at the Nterminus that is necessary for different viral processes (e.g. genome activation, virus replication and translation) $[2,7$, 9], and the C-terminal region responsible for dimer formation $[5,10]$.

PNRSV has been detected in many South American countries and in different host species. The prevalence of the virus in stone fruit trees in the central zone of Chile is $9.7 \%$ [28], while it reaches up to $25 \%$ in temperate zones in Argentina [14]. In Brazil, PNRSV has been detected in Rio Grande do Sul with a prevalence of $17 \%$ [16], while in Uruguay its prevalence is even higher, $48 \%$ [35]. In spite of the economic importance of stone fruit crops in South America, the molecular characterization of PNRSV isolates is scarce, except for one Argentinean isolate [24]. In the present work, the MP and CP genes of 23 PNRSV isolates from Chile, Brazil and Uruguay have been characterized and analyzed.

\section{Materials and methods}

Plant material and viral RNA extraction

Table 1 shows the different PNRSV isolates included in this study, with specific reference to the source tree variety and the symptoms they presented. Total nucleic acid

Table 1 Listing and properties of PNRSV isolates

\begin{tabular}{|c|c|c|c|c|c|c|c|c|}
\hline Isolate & Source & Origin & $\begin{array}{l}\text { Origin } \\
\text { of the variety }\end{array}$ & Symptomatology & Group & $\begin{array}{l}\text { Sequence } \\
\text { code }\end{array}$ & $\begin{array}{l}\text { Accession } \\
\text { number CP }\end{array}$ & $\begin{array}{l}\text { Accession } \\
\text { number MP }\end{array}$ \\
\hline 453 & Almond cv. Carmel & Chile & USA & Chlorotic pattern & PV96-II & AlmCl.car1 & EF565247 & EF565224 \\
\hline 553 & Cherry cv. Corazón de Paloma & Chile & Unknown & Asymptomatic & PV32-I & ChrCl.cor1 & EF565248 & EF565225 \\
\hline 564 & Cherry cv. Bing & Chile & USA & Chlorotic pattern & PV96-II & ChrCl.bin 1 & EF565249 & EF565226 \\
\hline 585 & Cherry cv. Sweet Hard & Chile & Canada & Asymptomatic & PV32-I & ChrCl.swe1 & EF565250 & EF565227 \\
\hline 775 & Cherry cv. Royal Down & Chile & USA & Ugly fruit & PV96-II & ChrCl.roy1 & EF565251 & EF565228 \\
\hline 113 & Nectarine cv. Early John & Chile & USA & Asymptomatic & PV96-II & NctCl.ear1 & EF565252 & EF565229 \\
\hline 73 & Nectarine cv. August Fire & Chile & USA & Asymptomatic & PE5-III & NctCl.aug1 & EF565253 & EF565230 \\
\hline 26 & Peach cv. Pomona & Chile & USA & Chlorotic pattern & PV96-II & PchCl.pom1 & EF565254 & EF565231 \\
\hline 437 & Peach cv. Loadell & Chile & USA & Chlorotic pattern & PV96-II & PchCl.loa1 & EF565255 & EF565232 \\
\hline 435 & Peach cv. Loadell & Chile & USA & Chlorotic pattern & PV96-II & PchCl.loa2 & EF565256 & EF565233 \\
\hline 487 & Peach cv. Rich Lady & Chile & USA & Chlorotic pattern & PV96-II & PchCl.ric1 & EF565257 & EF565234 \\
\hline 518 & Peach cv. August Lady & Chile & USA & Chlorotic pattern & PV96-II & PchCl.aug1 & EF565258 & EF565235 \\
\hline 526 & Peach cv. Summer Lady & Chile & USA & Chlorotic pattern & PV32-I & PchCl.sum1 & EF565259 & EF565236 \\
\hline 532 & Plum cv. Mirabolan & Chile & USA & Arabesques & PV96-II & PlmCl.mrb1 & EF565260 & EF565237 \\
\hline 474 & Plum cv. Black Ambar & Chile & USA & Chlorotic pattern & PV32-I & PlmCl.bla1 & EF565261 & EF565238 \\
\hline 478 & Plum cv. Friar & Chile & USA & Chlorotic pattern & PV96-II & PlmCl.fri1 & EF565262 & EF565239 \\
\hline 444 & Plum cv. D’Agen & Chile & France & Chlorotic pattern & PV96-II & PlmCl.dag1 & EF565263 & EF565240 \\
\hline MS3 & Peach cv. Marli & Brazil & Brazil & Asymptomatic & PV32-I & PchBr.unk1 & EF565264 & EF565241 \\
\hline MS4 & Peach cv. Marli & Brazil & Brazil & Asymptomatic & PV32-I & PchBr.unk2 & EF565265 & EF565242 \\
\hline M1 & Peach cv. Marli & Brazil & Brazil & Asymptomatic & PV96-II & PchBr.unk3 & EF565266 & EF565243 \\
\hline 15 & Plum cv. Golden Japan & Uruguay & Unknown & Not Available & PV96-II & PlmUy.gol1 & EF565267 & EF565244 \\
\hline 19 & Peach cv. Early Grande & Uruguay & Unknown & Not Available & PV32-I & PchUy.ear1 & EF565268 & EF565245 \\
\hline 36 & Peach cv. June Gold & Uruguay & Unknown & Chlorotic pattern & PV32-I & PchUy.jun1 & EF565269 & EF565246 \\
\hline 1 & Peach cv. Criollo & Argentina & Unknown & Not Available & PV32-I & PchAr.cri1 & AY007217 & \\
\hline PV96 & & & & & & PV96 & S78312 & \\
\hline PV32 & & & & & & PV32 & Y07568 & \\
\hline PE5 & & & & & & PE5 & L38823 & \\
\hline
\end{tabular}


extraction was performed from $0.2 \mathrm{~g}$ of leaves using the silica capture extraction protocol [34]. The extracted nucleic acids were stored at $-80^{\circ} \mathrm{C}$ until use.

\section{Amplification and cloning of genome sequences}

Primers flanking the MP and CP genes were designed from the sequence available in the database [42] (accession number Y07568; Table 1). The reverse transcription reaction was done in $20 \mu \mathrm{l}$ containing $1 \mu \mathrm{l}$ of $10 \% \mathrm{PVP}, 1 \mathrm{mM}$ of each dNTP, $40 \mathrm{U}$ of ribonuclease inhibitor (Amersham International, Cleveland), $10 \mathrm{U}$ of RevertAid ${ }^{\mathrm{TM}}$ Minus MMuLV RT (MBI Fermentas), 100 pmol of each antisense primer (see Table 2) and $1 \mu \mathrm{g}$ of total nucleic acids extracted from infected tissue. PCR reactions were done in $50 \mu \mathrm{l}$ containing $1 \mu \mathrm{l}$ of $10 \%$ PVP, $3 \mu \mathrm{l}$ of the reverse transcription reaction, $0.5 \mathrm{mM}$ of each dNTP, $5 \mu \mathrm{l}$ of $10 \times$ buffer $\left(166 \mathrm{mM}\left(\mathrm{NH}_{4}\right)_{2} \mathrm{SO}_{4}, 670 \mathrm{mM}\right.$ Tris- $\mathrm{HCl}$ at $\mathrm{pH} 8.8$ and Tween 20), $1 \mathrm{U}$ of EcoTaq DNA polymerase (Ecogen SRL, London), and 100 pmol of each primer (Table 2). PCR reaction was performed in a Perkin Elmer 2400 thermal cycler with an incubation at $94^{\circ} \mathrm{C}$ for 2 min followed by thirty cycles at $94^{\circ} \mathrm{C}$ for $30 \mathrm{~s}, 52^{\circ} \mathrm{C}$ for $30 \mathrm{~s}$ and $72^{\circ} \mathrm{C}$ for $30 \mathrm{~s}$ and a final incubation at $72^{\circ} \mathrm{C}$ for $10 \mathrm{~min}$. Amplified products were electrophoresed in $1 \%$ agarose gels in TAE (40 mM Tris-acetate, 1 mM EDTA, pH 8.0), stained with ethidium bromide and extracted with the QIAGEN Tip-20 (QIAGEN Inc., USA). The PCR fragments were directly sequenced by the dideoxynucleotide chain-termination method in an automated sequencer (ABI 3100 Genetic Analyzer; Perkin Elmer Applied Biosystem) using the primers employed for the amplification of both genes. In the case of the MP gene, two additional internal primers were used to sequence the full gene (VP239 and VP951; Table 2).

Sequence alignments and phylogenetic analyses

Amino acid alignments for MP and $\mathrm{CP}$ were obtained using MUSCLE version 3.52 [15]. Nucleotide sequences were then aligned by concatenating triplets according to the amino acid sequence alignment using the DAMBE version 4.2.13 [49]. The phylogenetic analysis of the MP and CP genes were inferred in a multi-step process: in the first step, the model of amino acid substitution that maximized the likelihood of the observations was inferred using the PROTTEST version 1.0.6 [1]. The JTT empirical matrix [29] was chosen as the model of amino acid substitution that better explained the observed pattern of genetic variability for both proteins. In a second step, neighbor-joining phylogenetic trees, using the JTT model, were obtained using the MEGA version 3.1 [32]. Third, the statistical reliability of the constructed trees was assessed by the bootstrap method based on 1,000 pseudoreplicates. The homologous sequences of apple mosaic virus (ApMV) were used for rooting purposes (accession number U15608). Finally, to further explore the reliability of certain branches in the trees, the four-cluster likelihoodmapping technique [44] was employed, as implemented in TREEPUZZLE version 5.2, with 10,000 puzzling steps.

The difference between nonsynonymous $\left(d_{\mathrm{N}}\right)$ and synonymous $\left(d_{\mathrm{S}}\right)$ substitution rates $\left(d_{\mathrm{N}}-d_{\mathrm{S}}\right)$ was employed as a proxy to seek the sign and intensity of the natural selection acting on different amino acids sites. This difference was estimated for each position in the alignments using the random-effects likelihood (REL) method [39] implemented in the HYPHY server (http://www.datamonkey.org). Standard errors were computed by the bootstrap method (based on 1,000 pseudoreplicates). A value $>0$ is taken as evidence for positive or directional selection, whereas values $<0$ are a signature for negative or purifying selection.

Transmembrane motifs were predicted by the online PREDICTPROTEIN software (http://www.cubic.bioc. columbia.edu/predictprotein/).

\section{Results and discussion}

PNRSV is distributed worldwide and is probably one of the plant viruses for which the most different isolates have been characterized, principally from the USA, Europe and the Mediterranean area. However, data for PNRSV isolates
Table 2 List of primers used for PCR amplification and DNA sequencing

Underlining indicates extra nucleotides designed to introduce specific restriction sites

a Antisense primer

b Sense primer

\begin{tabular}{llcl}
\hline Primer & Sequence & $\begin{array}{l}\text { Location in the } \\
\text { viral RNA 3 (nt) }\end{array}$ & Target gene \\
\hline MPf $^{\text {s }}$ & $5^{\prime}$-TTTGGATCCGATTGTTGGTTGTCTTTTC & $124-142$ & MP \\
MPr $^{\text {a }}$ & $5^{\prime}$-TTTAAGCTTATTGCAAATTCGGCAAAAC & $1,105-1,123$ & MP \\
VP81 $^{\text {b }}$ & $5^{\prime}$-AGTGGATCCATGGTTTGCCGAATTTGC & $1,103-1,120$ & CP \\
VP103 $^{\text {a }}$ & $5^{\prime}$-ACATAAGCTTCTAGATCTCAAGCAGGTC & $1,765-1,783$ & CP \\
VP239 $^{\text {b }}$ & $5^{\prime}$-GGCCGTGTATTCCTCGTTTATGTA & $438-461$ & MP \\
VP951 $^{\text {a }}$ & $5^{\prime}$-CACAGCTAGCCGGGAATAAAATAGGATTC & $731-749$ & MP \\
\hline
\end{tabular}


from South America are scarce. In the present study, the molecular variability of the movement (MP) and coat (CP) protein genes from 23 isolates from Chile, Uruguay, and Brazil has been analyzed.

The deduced amino acids sequences of the MP and CP genes ranged between 283-284 and 224-226 residues, respectively. The average amino acid identities among South American isolates had percentage values of 91.5100 and 89.7-100, respectively. The alignments for the two genes (Fig. 1) confirm that South American isolates belong to the same three phylogroups of the PNRSV isolates previously described PV32-I, PV96-II and PE5-III [3, 4, $22,48]$.

The distribution into phylogroups of the 45 previously characterized PNRSV isolates from North America, Europe and the Mediterranean area was 57.8, 31.1, and $11.1 \%$ for PV96-II, PV32-I, and PE5-III, respectively [4]. No significant differences were detected between the frequency distribution of phylogroups among the 24 South American isolates $\left(58.3,37.5\right.$ and $4.2 \% ; \chi^{2}=3.805,2$ d.f., $P=0.149$ ) and those from the rest of the world. Therefore, it is statistically justified to pool all samples and to compute an overall expected distribution for the members of each phylogroup (58.0\% PV96-II, 33.3\% PV32-I and 8.7\% PE5-III) that should be valid irrespective of the geographic area and host species sampled. Furthermore, this frequency distribution of phylogroups may represent an equilibrium distribution in which the abundance of a given type depends on factors such as its fitness, growth, and transmission rates under different environmental conditions and in different host species. However, it is worth noting the low number of PNRSV isolates assigned to the PE5-III phylogroup (6 out of 69) and the previous observation that the PE5-III phylogroup has an accelerated rate of molecular evolution for the MP and CP genes [11]. Collectively, these observations suggest that selective pressures acting on PE5-III isolates are stronger than on other phylogroups. Which specific pressures act on PE5-III, and particularly, whether its actual frequency is stable or transiently changing toward higher levels, which may suggest a faster rate of molecular evolution, is still a question to be explored.

Functional relevance of the observed variability in MP

In the case of the MP, the intra-group amino acid identities ranged between 96.5-100, 96.8-98.9 and 98.9\% among isolates belonging to the PV96-II, PV32-I, and PE5-III phylogroups, respectively, which are in the same range as the previously reported values [4]. The alignment of MP sequences (Fig. 1a) shows a highly conserved protein, except for the C-terminus, which contains the majority of the differences among all isolates. This portion of the
Fig. 1 Amino acid alignment of the movement $(M P)$ (a) and coat $(C P)$ proteins (b) of the 23 South American PNRSV isolates characterized in this work. In bold, isolates previously characterized and used to represent the three phylogroups (PV32-I, PV96-II and PE5-III; see Table 1). Dots indicate identical residues, whereas dashes denote gaps in the sequence. The dash at position 258 of the MP is included to maintain the same numbering when all PNRSV isolates sequenced so far are included. The basic region carrying critical residues for the RNA binding of the MP [26] is underlined with the basic residues in bold. The C-terminal region that aligned with the C-terminal 44 amino acids of AMV MP, which specifically interact with the cognate $\mathrm{CP}$ [40], are doubly underlined. The basic residues critical for the RNA-binding properties of the $\mathrm{CP}$ [7] are highlighted in bold. The C-terminal region required for dimer formation is underlined [5]. The amino acid sequences of the PNRSV isolates PV96, PV32 and PE5 are included. Numbers at the top represent the corresponding residues in the full-length protein

protein has been postulated by covariation analysis to interact with the $\mathrm{N}$-terminus of the cognate $\mathrm{CP}$, in which E256 of the MP could interact with T52 of the CP [11]. Direct evidence of such interaction has been reported for the closely related AMV, in which the C-terminal 44 amino acids of the MP interact with the cognate CP [40]. Interestingly, the C-terminal 44 amino acids of the AMV MP aligned with the variable $\mathrm{C}$-terminal 35 amino acids of the PNRSV MP (Fig. 1a). Most viral MPs have an RNAbinding domain, required for the cell-to-cell movement, that is characterized by an accumulation of basic residues. This domain has been mapped between residues 56-88 of the PNRSV MP, which carries nine basic residues [26]. Mutational analysis of the different basic residues showed that the substitution of three out of nine amino acids is sufficient to reduce the RNA binding affinity of the MP and also to block cell-to-cell transport without affecting other viral properties [27]. Interestingly, the nine basic residues of the RNA-binding domains are conserved in all PNRSV isolates sequenced so far except for isolate NecSp.mur [4], which contains a shorter version of only eight residues. This domain is also highly conserved among all isolates presented herein, including the nine basic residues. Furthermore, all isolates belonging to the PV32-I and PE5-III phylogroups contain an extra basic residue (K81). This peculiarity is a general rule for all isolates belonging to the two groups except for the PV32 isolate. The observation that isolate PchBr.unk1 contains two extra basic residues (R75, K81) allows it to be argued that it is possible that a functional RNA-binding domain requires from eight to eleven basic residues. This observation may reflect a range of biological RNA binding affinities in which extreme RNA interactions (strong or low) are incompatible with other processes during the viral life cycle (e.g., replication, encapsidation, etc). In this sense, the dissociation constant $\left(K_{d}\right)$ for the PNRSV MP-RNA complex was estimated to be $1.4 \mu \mathrm{M}$ [26], which is within the range of the values 


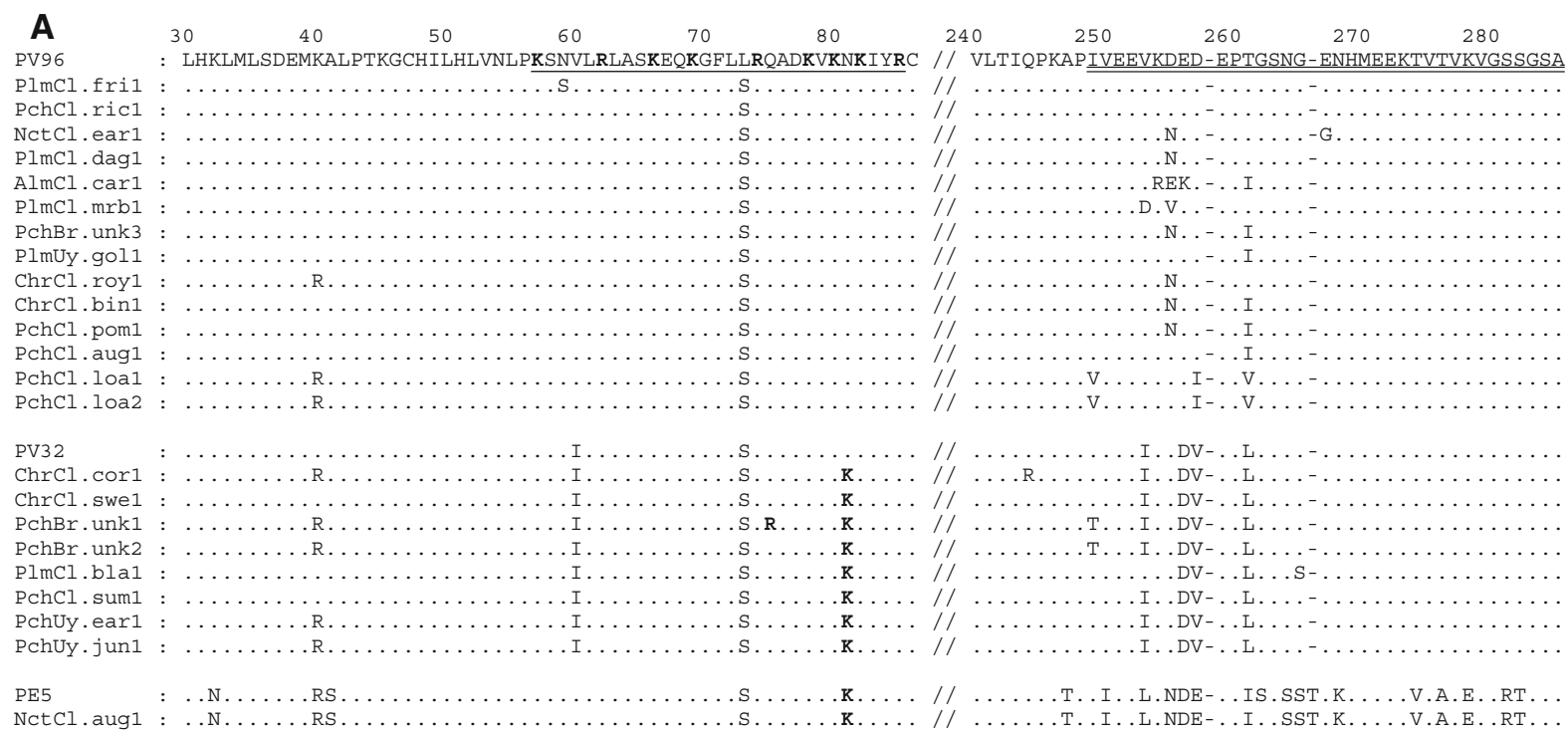

$\begin{array}{lllllllllll}\text { B } & 20 & 30 & 40 & 50 & 60 & 70 & 80 & 110 & 120 & 130\end{array}$ PV96 : CHPNGALVPLRAQQRAANNPNR--NPNRASSGTGPAVRPQPVVKTTWTVRGPNVPPRIPKGFV /// MGQNLTLLTVIVRMNSMSSNGWIGMVEDYKVERPDGPNALS PlmCl.fril : PchCl.ricl NctCl.ear1 Plmel.dag1 PlmCl.mrb1 PchBr.unk 3 PlmUy.gol1 Chrcl.roy 1
Chrcl.bin1 PchCl.pom1 Pchcl.aug1 Pchcl.loal Pchcl. loa2

PV32

PchAr.cril

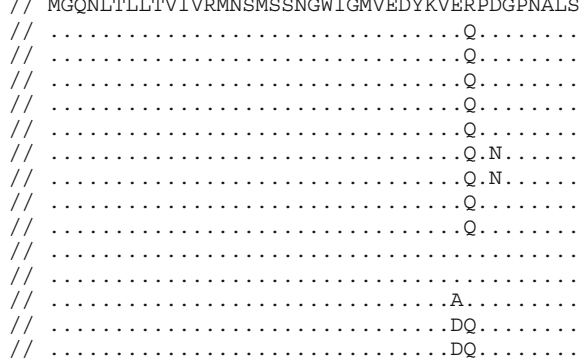

Chrcl.cor 1

PchBr.unk1

PchBr. unk2

PlmCl.blal

PchCl. suml

PchUy . ear1
PchUy.jun1

PE5
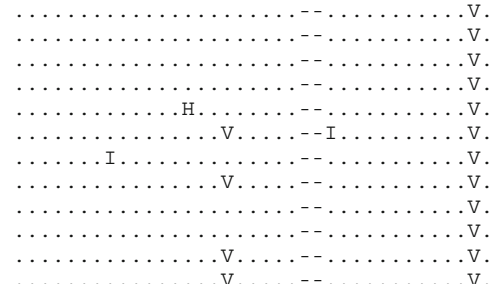

N.
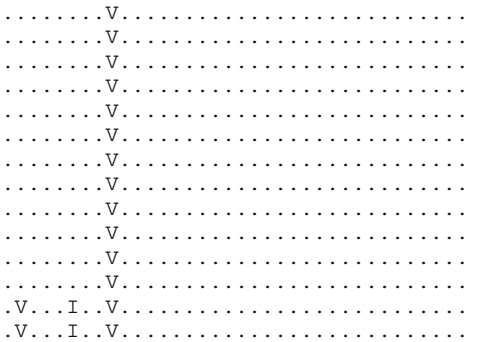

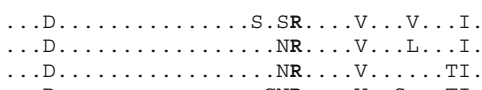

GNR . . .V. . S . TI S .

. NR . . . V. . I.

NR . V . . . . . . . . . . . .

NR...V...I

.NR . . . V . . I

.NR . . . . . . I.

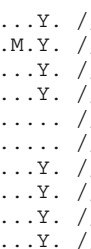

. DQ.

WD.

...D. . . .

D. D.

.V.V.NVV......K. .

NCtCl.aug1

PV96

PlmCl.fril

Pchcl.ricl:

NctCl.ear1 : /

Plmcl.dag1 : //

PchBr.unk 3

PlmUy.gol1 : /

Chrcl.royl : //

Chrcl.bin1 : //

PchCl.pom1 : //

PchCl.aug1 : /

Pchcl.loal : //

PchCl. loa2

PV32

PchAr.cril:

Chrcl.corl : /

Plmcl.bla1 :

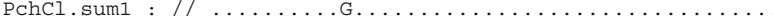

PchUy ear1: /

PchUy jun 1 :

PE 5

$\begin{array}{llll}\text { PE5 } & : & / / & \ldots I . \\ \text { NCtCl.aug1 } & : & / / & \ldots I\end{array}$ 
reported for other viral MPs such as those from cucumber mosaic virus (CMV) [31], TMV [33], brome mosaic virus (BMV) [18] and cowpea chlorotic mottle virus [17]. The observation that the MPs of PNRSV, CMV, BMV, and TMV are functionally interchangeable with the MP of AMV [40] supports the idea of a similar biological RNA binding affinity in vivo for the abovementioned viral MPs.

The alignment of all of the PNRSV MP sequences sequenced so far highlights the existence of residues representative of the PV32-I, PV96-II and PE5-III phylogroups. Residue D/I257 is specific for the PV96-II group (with the exception of the SW6 isolate from cherry, AF013287) meanwhile, amino acids V257 and L261 are representative of the PV32-I group. The PE5-III group contains a large number of specific residues with N32, S/ H41, I250, L253, E/G257, S/I264, T266, V274, R/G281 and T282. Below, we will analyze in more detail the relationship between isolate SW6 and the rest of PNRSV groups. With the exception of residues N32 and S/H41, the rest of the specific residues are located at the variable $\mathrm{C}$ terminal region, which has been postulated herein to interact with the cognate coat protein [11]. Residues V257 and L261 have been identified in the group of eight amino acids that allowed $\mathrm{CH} 9$ serotypes causing a rugose mosaic disease to be differentiated from those causing mild mottling in sweet cherry.

Functional relevance of the observed variability in $\mathrm{CP}$

The alignment of CP sequences (Fig. 1b) shows a highly conserved protein, except at its N-terminus, where most of the differences among all isolates are contained. The South American PNRSV isolates grouped into the same PV96-II, PV32-I and PE5-III phylogroups obtained with the MP gene, and the intragroup amino acid identity values ranged between 96-100, 95.6-100 and 97.8\%, respectively. The analysis of all isolates sequenced so far shows the existence of certain phylogroup-specific residues for PV32-I and PE5-III but not for PV96-II. Isolates belonging to PV32-I are characterized by the presence of two extra residues (N/ S42 and R43) and the amino acid Y81. Only isolates $\mathrm{CH} 38$ (AF034991) and CH57 (AF034993) or PchBr.unk1 and PchBr.unk2 from the PV32-I group do not contain the additional amino acids or the Y81 residue, respectively. Residues K59, N121, R139, N142 and I181 are specific of phylogroup PE5-III (Fig. 1b). Remarkably, the extra residues of the PV32-I group are inside of the RNA-binding domain described for PNRSV (amino acids 25-50; Fig. 1b) [7]. This motif contains four $\mathrm{R}$ residues (five in the PV32-I group) that are critical for the RNA binding capacity of the CP. All PNRSV isolates sequenced so far have the four basic residues except $\mathrm{ChrCl}$.swe1, which contains only three. The extra R observed in the PV32-I phylogroup could contribute to the RNA-binding capacity of the $\mathrm{CP}$. The $K_{\mathrm{d}}$ observed for a synthetic peptide corresponding to the RNA-binding domain of an PNRSV (isolate PV32) that carries the five basic residues was estimated to be $17 \mu \mathrm{M}$, whereas it was $11.3 \mathrm{nM}$ for the entire protein [7]. This discrepancy was explained by the presence of a putative zinc finger domain at the N-terminus [42]. Replacement of some $\mathrm{R}$ residues located at the RNA-binding domain by $\mathrm{A}$ significantly reduced the RNA interaction capacity of the synthetic peptide [7]. However, isolate ChrCl.swe1 lacks one of the critical $\mathrm{R}$ residues. This observation suggests that at least one of the mutated RNA-binding domains, characterized in vitro as having a low RNA-binding affinity, is still functional in vivo in the context of the full protein, indicating that other domains might contribute to the RNA interaction capacity (e.g. zinc finger domain). The observation that all $\mathrm{R}$ amino acids of the domain contribute to the RNA affinity of the CP [7] suggests that there is a functional range, with a $K_{\mathrm{d}}$ of $11.3 \mathrm{nM}$ (five R) [7] or larger (four R). In this sense, the PNRSV CP of isolate PV96 that carries four basic residues is functionally interchangeable with the AMV CP, whose $K_{d}$ is $500 \mathrm{nM}[8,43]$. Covariation analyses of PNRSV CP [11] identified a significant association between the residues at sites V48 and D141.

\section{Implications for MP and CP interactions}

When covariation analyses were extended to detect MP and CP interactions, the MP residues V253, E256, D257, and T261 (I261 in the alignment used in [11]) were seen to covary with the $\mathrm{CP}$ residues T52 and E141, suggesting a putative MP-CP interaction across these regions. Considering all the PNRSV isolates available, the sequences of the MP and CP covarying residues that are characteristic of the PV32-I group are I/V253-D256-V257-L261 and L/V/ M/T/I52-D141, while the covarying residues defining the PV96-II group are V/D253-E/K256-D257-T/I261 and T/A/ V/I52-A/E141, except for the SW6, Pch.loa1 and 2 isolates, which have a consensus sequence more similar to that of the PV32 group (I/V253-E256-I/V257-V261 and I52-D/ N141). Apparently, the presence of an aliphatic residue at MP position 257 (I or $\mathrm{V}$ ) correlates with the presence of a $\mathrm{D} / \mathrm{N}$ at $\mathrm{CP}$ position 141. This observation suggests that the putative MP-CP interaction for isolates SW6, Pch.loa1 and Pch.loa2 may be more similar to those, which characterize the PV32-I group than to those which characterize the PV96-III group.

Phylogenetic inferences

Previous phylogenetic analyses of the PNRSV MP and CP sequences suggested a division into three groups whose 
representative members are isolates PV32, PV96 and PE5 $[3,4]$. A similar grouping was later confirmed by Vasková et al. [48], although they proposed an alternative nomenclature for each phylogroup (I, II and III, respectively). Phylogenetic analysis of the MP and CP sequences from the 23 South American isolates characterized herein plus all of the isolates analyzed by Codoñer et al. [11] further supports the existence of the same three phylogroups, irrespective of the protein employed for the analysis (Fig. 2). However, the statistical support for the internal nodes in the phylogenetic tree is, in general, higher in the MP tree than in the CP tree (Fig. 2). The South American isolates were evenly distributed into the three groups, confirming a lack of clustering by geographical origin. However, considering the pollen transmission of PNRSV and the asexual propagation of stone fruit trees, a North American origin for these isolates cannot be ruled out since most Prunus varieties come from this geographic region (Table 1). Similarly, clustering does not reflect host species or symptomatology, thus confirming earlier reports [3, 4, 22, 46, 48]. In this sense, most South American isolates clustered into the PV96-II phylogroup cause not only the characteristic mild symptoms but also severe disorders. Moreover, some of the isolates included in the PV32-I phylogroup, which mostly contains isolates causing severe symptoms, were asymptomatic (Table 1).

The phylogenetic positions of isolates PchCL.loa1 and PchCL.loa2 were not well resolved in the CP tree, with a bootstrap value of $42 \%$ (Fig. $2 \mathrm{~b}$ ). In addition, both isolates were closely related to isolate SW6, a cherry variant that was grouped outside of the three PNRSV groups [11, 22]. To further test to which PNRSV group these three isolates belong, an alternative statistical approach, the four-cluster likelihood-mapping method, was employed. Figure 3 shows the results of this analysis. In the case of the MP, $72.5 \%$ of all of the quartets supported the branching pattern that groups the three isolates (SW6 cluster) and the PV96-II phylogroup versus the remaining sequences. Somewhat less statistical support for this hypothesis was provided by the CP (59.3\%). Therefore, based on likelihood mapping, extra support for the inclusion of isolates PchCL.loa1, PchCL.loa2 and SW6 within the PV96-II phylogroup has been provided. Since the main differences between these isolates and the rest of the PV96-II isolates are located at the putative MP-CP interaction residues, the low statistical support may reflect an interesting biological phenomenon: typical PV96-II MP and CP proteins that are interacting as PV32-I proteins do. It would be very interesting to explore the interchangeability of the CP gene between PV32-I and PV96-II phylogroups to confirm this hypothesis.
Targets of natural selection

Considering the already large number of PNRSV sequences available in the database, we decided to analyze which particular MP and CP amino acid sites were under selective constraints. To this end, the difference between nonsynonymous $\left(d_{N}\right)$ and synonymous $\left(d_{S}\right)$ substitution rates $d_{N}-$ $d_{S}$ has been used to evaluate the sign and intensity of selection. For the MP, 40 sites were found to be under negative selection and only one site was found to be under positive selection ( $p<0.05$; Fig. 4 ). In the case of CP, 13 sites were predicted to be under negative selection (Fig. 4b).

Regarding the MP, four of the selected sites are located at the previously characterized RNA-binding motif (S65, E67, G70, and D77) [26]. Interestingly, none of the negatively selected sites correspond to the basic residues that are critical for the RNA-binding capacity. This observation suggests that selection is probably acting on the maintenance of the right secondary/tertiary conformation of the RNA-binding motif. The next six negatively selected amino acid sites (R89, Y94, I97, I98, Q99, and T102) are located inside of the predicted transmembrane domain [42], with 197 and 198 showing the most negative differences. This transmembrane region is highly conserved across all MPs related to the $30 \mathrm{~K}$ superfamily (the $\beta$ - 1 and $\beta$ - 2 sections of the MP as described by Melcher et al. [36]). The MP region preceding the $\mathrm{C}$-terminal 35 residues allowed the accumulation of selected sites with large negative differences (V231, D236, R238, T242 and P248). It has to be mentioned that no function has been determined for these domains, although we found that a PNRSV MP mutant carrying the N-terminal 245 residues is still functionally interchangeable with the corresponding gene of AMV while a mutant carrying the N-terminal 235 is not (data not shown). The C-terminal 35 residues have been postulated to interact with the cognate $\mathrm{CP}$ (see above; Fig. 1b). This C-terminal portion of the protein contains four sites selected under negative selection (I249, T274, V279 and G280) and the only amino acid site predicted to be under positive selection (D255).

In the case of the $\mathrm{CP}$, the selected sites are not related to any of the previously characterized domains except for the C-terminal region responsible for dimer formation (D206, Q211 and T214), which is highly conserved in all members of the genus Ilarvirus sequenced to date [5, 25].

In summary, the results presented herein show that all of the PNRSV isolates characterized in South America perfectly group into the three previously described PNRSV phylogroups and share all of the characterized motifs in both their MP and CP molecules. 


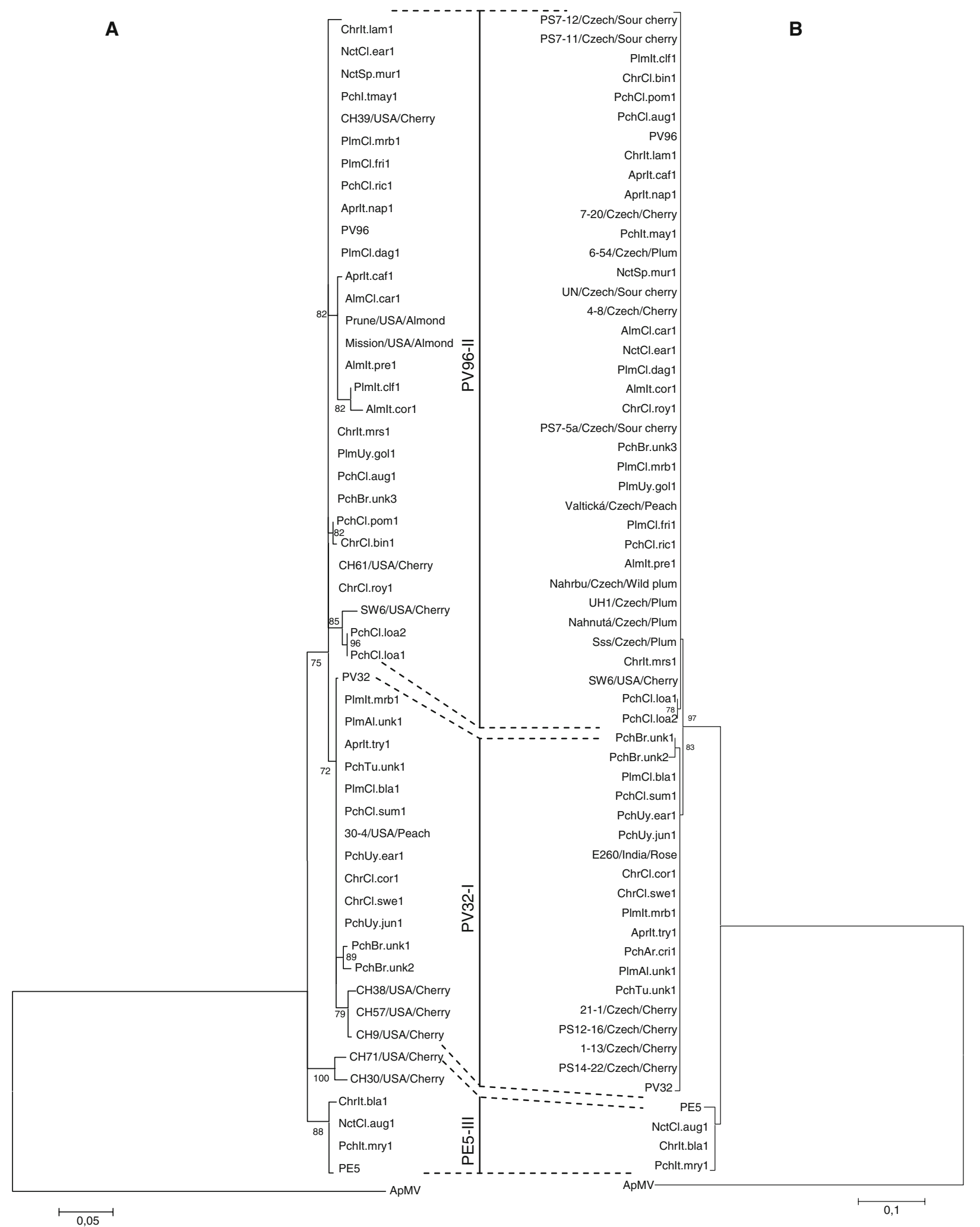

Fig. 2 Phylogenetic trees of MP (a) and CP (b). The analysis was performed with the 23 PNRSV isolates described here plus isolates analyzed previously by Codoñer et al. [11]. Trees were inferred by the minimum-evolution method. Numbers at the nodes represent bootstrap support values based on 10,000 pseudoreplicates. Nodes with bootstrap support $<50 \%$ have been collapsed. Amino acid sequences representative of the three subgroups are include (PV96, PV32 and PE5). The CP sequence of the Argentine PNRSV isolate (PchAr.cri1, AY007217) has been included in $\mathbf{b}$. The trees are rooted to the corresponding amino acids sequences of ApMV (Accession number U15608) 
Fig. 3 Quartet likelihoodmapping analysis supporting the inclusion of isolates SW6, PchCl.loa1 and PchCl.loa2 (SW6 cluster) as members of the PNRSV phylogroup PV96-II
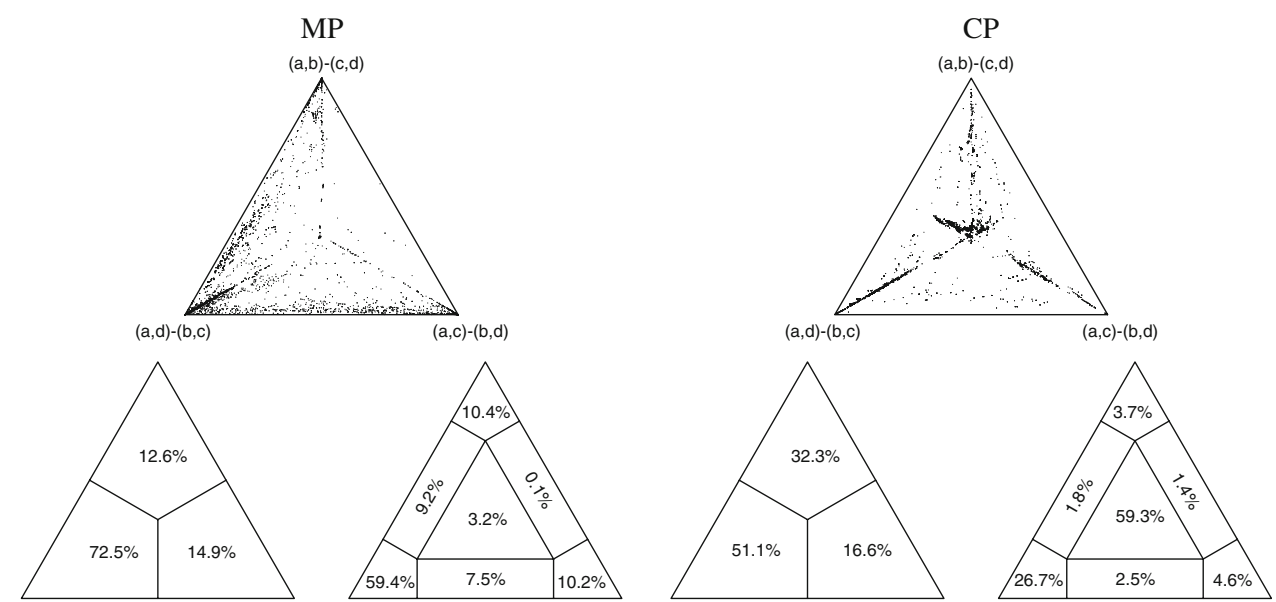

PV32 group (a)

(b) PV96 group

(c) SW6 cluster

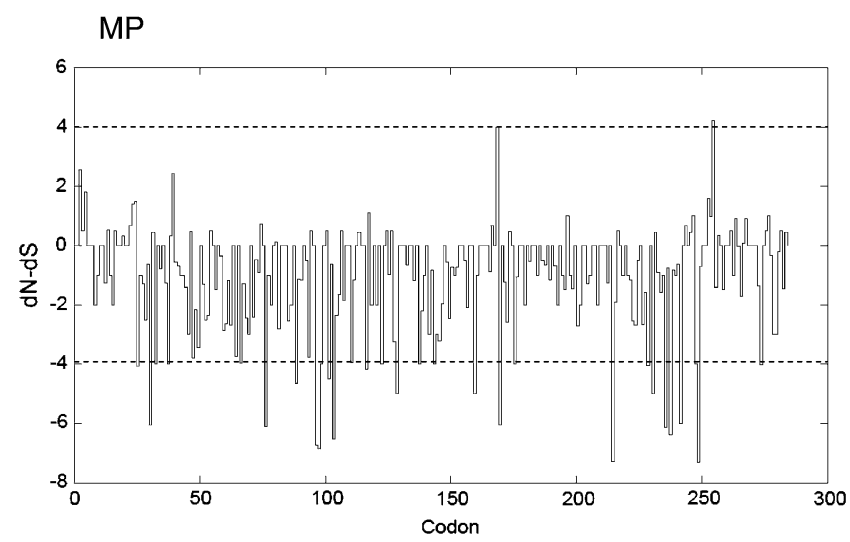

\begin{tabular}{ccc} 
CODON & $d_{N}-d_{S}$ & $p$-value \\
\hline $255(\mathrm{D})$ & 4,21 & 0,0484 \\
$26(\mathrm{I})$ & $-4,07$ & 0,0268 \\
$31(\mathrm{H})$ & $-6,05$ & 0,0015 \\
$33(\mathrm{~L})$ & -4 & 0,0123 \\
$38(\mathrm{E})$ & $-3,98$ & 0,0191 \\
$46(\mathrm{G})$ & -3 & 0,037 \\
$48(\mathrm{H})$ & $-3,78$ & 0,0184 \\
$50(\mathrm{~L})$ & $-3,43$ & 0,0438 \\
$65(\mathrm{~S})$ & $-3,74$ & 0,019 \\
$67(\mathrm{E})$ & $-3,97$ & 0,0193 \\
$70(\mathrm{G})$ & -3 & 0,037 \\
$77(\mathrm{D})$ & $-6,09$ & 0,0015 \\
$89(\mathrm{R})$ & $-4,63$ & 0,0183 \\
$94(\mathrm{Y})$ & $-3,76$ & 0,0231 \\
$97(\mathrm{I})$ & $-6,71$ & 0,0006 \\
$98(\mathrm{I})$ & $-6,84$ & 0,0008 \\
$99(\mathrm{Q})$ & $-3,99$ & 0,0437 \\
$102(\mathrm{~T})$ & $-4,5$ & 0,0178 \\
$104(\mathrm{G})$ & $-6,53$ & 0,0025 \\
$111(\mathrm{Q})$ & $-3,94$ & 0,0452 \\
$117(\mathrm{E})$ & $-4,17$ & 0,0166 \\
\hline
\end{tabular}

\begin{tabular}{ccc} 
CODON & $d_{N}-d_{S}$ & $p$-value \\
\hline $123(\mathrm{~T})$ & -4 & 0,0123 \\
$129(\mathrm{R})$ & $-4,99$ & 0,0041 \\
$138(\mathrm{G})$ & -4 & 0,0146 \\
$142(\mathrm{~V})$ & -3 & 0,037 \\
$144(\mathrm{~S})$ & -4 & 0,0147 \\
$145(\mathrm{~A})$ & -3 & 0,037 \\
$160(\mathrm{P})$ & -5 & 0,0041 \\
$170(\mathrm{~F})$ & $-6,04$ & 0,0015 \\
$176(\mathrm{~S})$ & -4 & 0,0144 \\
$215(\mathrm{I})$ & $-7,27$ & 0,008 \\
$229(\mathrm{I})$ & $-4,03$ & 0,0272 \\
$231(\mathrm{~V})$ & -5 & 0,0041 \\
$236(\mathrm{D})$ & $-6,12$ & 0,0014 \\
$238(\mathrm{R})$ & $-6,36$ & 0,0016 \\
$242(\mathrm{~T})$ & -6 & 0,0013 \\
$248(\mathrm{P})$ & -4 & 0,0123 \\
$249(\mathrm{I})$ & $-7,3$ & 0,0125 \\
$274(\mathrm{~T})$ & -4 & 0,0449 \\
$279(\mathrm{~V})$ & -3 & 0,037 \\
$280(\mathrm{G})$ & -3 & 0,037 \\
& & \\
\hline
\end{tabular}

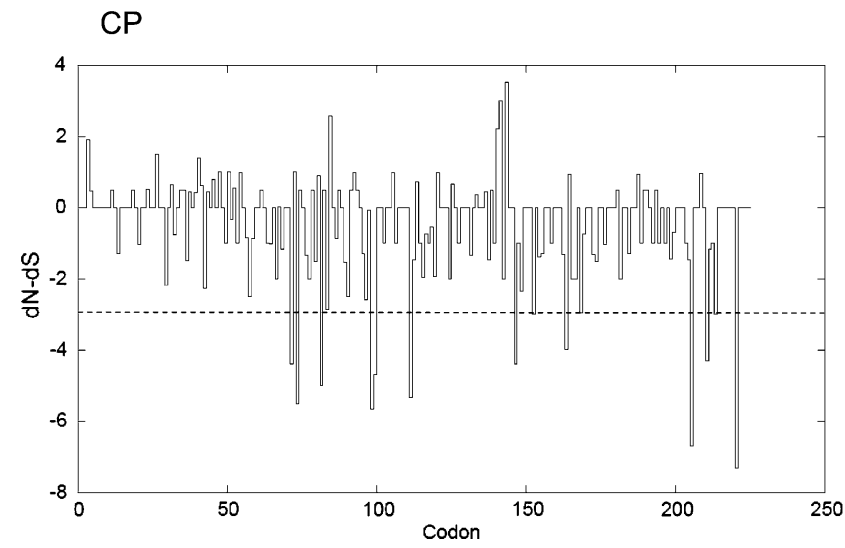

\begin{tabular}{ccc} 
CODON & $d_{N}-d_{S}$ & $p$-value \\
\hline $72(\mathrm{~N})$ & $-4,39$ & 0,0117 \\
$74(\mathrm{P})$ & $-5,5$ & 0,0068 \\
$82(\mathrm{~V})$ & -5 & 0,0041 \\
$99(\mathrm{~S})$ & $-5,65$ & 0,003 \\
$100(\mathrm{I})$ & $-4,68$ & 0,018 \\
$112(\mathrm{Q})$ & $-5,32$ & 0,0129 \\
$147(\mathrm{~N})$ & $-4,39$ & 0,0117 \\
$153(\mathrm{G})$ & -3 & 0,037 \\
$164(\mathrm{~F})$ & $-3,98$ & 0,0158 \\
$206(\mathrm{D})$ & $-6,68$ & 0,0033 \\
$211(\mathrm{Q})$ & $-4,29$ & 0,0308 \\
$214(\mathrm{~T})$ & -3 & 0,037 \\
$221(\mathrm{E})$ & $-7,3$ & 0,0008 \\
\hline
\end{tabular}

Fig. 4 Distribution of $d_{N}-d_{S}$ along the sequence of the MP and CP coding regions. Values were computed using a random effects likelihood (REL) method. The statistical significance of each value

was evaluated by its Bayesian posterior probability. Amino acids sites predicted to be under either a negative or positive selection are indicated with their corresponding $d_{\mathrm{N}}-d_{\mathrm{S}}$ and $P$-values 
Acknowledgments This work was supported by Grants BIO200507331-C02-01 and 2004CL0030 from the Ministerio de Educación y Ciencia and Consejo Superior de Investigaciones Científicas, respectively.

\section{References}

1. Abascal F, Zardoya R, Posada D (2005) ProtTest: selection of best-fit models of protein evolution. Bioinformatics 21:21042105

2. AnselMcKinney P, Scott SW, Swanson M, Ge X, Gehrke L (1996) A plant viral coat protein RNA binding consensus sequence contains a crucial arginine. EMBO J 15:5077-5084

3. Aparicio E, Myrta A, Di Terlizzi B, Pallás V (1999) Molecular variability among isolates of Prunus necrotic ringspot virus from different Prunus spp. Phytopathology 89:991-999

4. Aparicio F, Pallás V (2002) The molecular variability analysis of the RNA 3 of fifteen isolates of Prunus necrotic ringspot virus sheds light on the minimal requirements for the synthesis of its subgenomic RNA. Virus Genes 25:75-84

5. Aparicio F, Sánchez-Navarro JA, Pallás V (2006) In vitro and in vivo mapping of the Prunus necrotic ringspot virus coat protein C-terminal dimerization domain by bimolecular fluorescence complementation. J Gen Virol 87:1745-1750

6. Aparicio F, Sánchez-Pina MA, Sánchez-Navarro JA, Pallás V (1999) Location of Prunus necrotic ringspot ilarvirus within pollen grains of infected nectarine trees: evidence from RT-PCR, dot-blot and in situ hybridisation. Eur J Plant Pathol 105:623-627

7. Aparicio F, Vilar M, Perez-Paya E, Pallás V (2003) The coat protein of Prunus necrotic ringspot virus specifically binds to and regulates the conformation of its genomic RNA. Virology 313:213-223

8. Baer ML, Houser F, Loesch-Fries LS, Gehrke L (1994) Specific RNA binding by amino-terminal peptides of alfalfa mosaic virus coat protein. EMBO J 13:727-735

9. Bol JF (2005) Replication of alfamo- and ilarviruses: role of the coat protein. Annu Rev Phytopathol 43:39-62

10. Choi JW, Loesch-Fries LS (1999) Effect of C-terminal mutations of alfalfa mosaic virus coat protein on dimer formation and assembly in vitro. Virology 260:182-189

11. Codoñer FM, Fares MA, Elena SF (2006) Adaptive covariation between the coat and movement proteins of Prunus necrotic ringspot virus. J Virol 80:5833-5840

12. Cole A, Mink GI, Regev S (1982) Location of Prunus necrotic ringspot virus on pollen grains from infected almond and cherry trees. Phytopathology 72:1542-1545

13. Crosslin JM, Mink GI (1992) Biophysical differences among Prunus necrotic ringspot ilarviruses. Phytopathology 82:200-206

14. Dal Zotto A, Nome SF, Di Rienzo JA, Docampo DM (1999) Fluctuations of Prunus necrotic ringspot virus (PNRSV) at various phenological stages in peach cultivars. Plant Dis 83:10551057

15. Edgar RC (2004) MUSCLE: multiple sequence alignment with high accuracy and high throughput. Nucleic Acids Res 32:17921797

16. Fajardo TVM, Eiras M, Maciel SC, Daniels J, Nickel O (2004) Detecção e caracterização molecular parcial de Prune dwarf virus e Prunus necrotic ringspot virus em pessegueiros. Summa Phytopathologica 30:286-289

17. Fujita M, Mise K, Furusawa I (1999) Expression and characterization of the 3a movement protein of cowpea chlorotic mottle bromovirus. Arch Virol 144:2449-2456

18. Fujita M, Mise K, Kajiura Y, Dohi K, Furusawa I (1998) Nucleic acid-binding properties and subcellular localization of the $3 \mathrm{a}$ protein of brome mosaic bromovirus. J Gen Virol 79:1273-1280
19. Fulton RW (1983) Ilarvirus group. CMI/AAB descriptions of plant viruses no. 275, Wellesbourne, UK

20. George JA, Davidson TR (1964) Further evidence of pollen transmission of necrotic ring spot + sour cherry yellows viruses in sour cherry. Can J Plant Sci 44:383

21. Hamilton RI, Nichols C, Valentine B (1984) Survey for Prunus necrotic ringspot and other viruses contaminating the exine of pollen collected by bees. Can J Plant Pathol 6:196-199

22. Hammond RW (2003) Phylogeny of isolates of Prunus necrotic ringspot virus from the Ilarvirus ringtest and identification of group-specific features. Arch Virol 148:1195-1210

23. Hammond RW, Crosslin JM (1998) Virulence and molecular polymorphism of Prunus necrotic ringspot virus isolates. J Gen Virol 79:1815-1823

24. Helguera PR, Taborda R, Docampo DM, Ducasse DA (2001) Immunocapture reverse transcription-polymerase chain reaction combined with nested PCR greatly increases the detection of Prunus necrotic ring spot virus in the peach. J Virol Methods 95:93-100

25. Herranz MC, Al Rwahnih M, Sánchez-Navarro JA, Elena SF, Choueiri E, Myrta A, Pallás V (2007) Low genetic variability in the coat and movement proteins of American plum line pattern virus isolates from different geographic origins. Arch Virol (in press)

26. Herranz MC, Pallás V (2004) RNA-binding properties and mapping of the RNA-binding domain from the movement protein of Prunus necrotic ringspot virus. J Gen Virol 85:761-768

27. Herranz MC, Sánchez-Navarro JA, Sauri A, Mingarro I, Pallás V (2005) Mutational analysis of the RNA-binding domain of the Prunus necrotic ringspot virus (PNRSV) movement protein reveals its requirement for cell-to-cell movement. Virology 339:31-41

28. Herrera MG, Madariaga M (2002) Incidencia de los virus Prunus necrotic ringspot virus (PNRSV), Prune dwarf virus (PDV), Tomato ringspot virus (ToRSV) y Plum pox virus (PPV) en viveros de frutales de carozo en la zona central de Chile. Agricult Técnica 62:38-45

29. Jones DT, Taylor WR, Thornton JM (1992) The rapid generation of mutation data matrices from protein sequences. Comput Appl Biosci 8:275-282

30. Kelley RD, Cameron HR (1986) Location of prune dwarf and Prunus necrotic ringspot viruses associated with sweet cherry pollen and seed. Phytopathology 76:317-322

31. Kim SH, Kalinina NO, Andreev I, Ryabov EV, Fitzgerald AG, Taliansky ME, Palukaitis P (2004) The C-terminal 33 amino acids of the cucumber mosaic virus $3 \mathrm{a}$ protein affect virus movement, RNA binding and inhibition of infection and translation. J Gen Virol 85:221-230

32. Kumar S, Tamura K, Nei M (2004) MEGA3: integrated software for molecular evolutionary genetics analysis and sequence alignment. Brief Bioinform 5:150-163

33. Li QB, Palukaitis P (1996) Comparison of the nucleic acid- and NTP-binding properties of the movement protein of cucumber mosaic cucumovirus and tobacco mosaic tobamovirus. Virology 216:71-79

34. MacKenzie DJ, Mclean MA, Mukerji S, Green M (1997) Improved RNA extraction from woody plants for the detection of viral pathogens by reverse transcription-polymerase chain reaction. Plant Dis 81:222-226

35. Maeso Tozzi TC, Tanaka H, Soria J (1995) Studies on fruit tree viruses in Uruguay. Acta Hortic 386:155-164

36. Melcher U (2000) The ' $30 \mathrm{~K}$ ' superfamily of viral movement proteins. J Gen Virol 81:257-266

37. Mink GI (1992) Prunus necrotic ringspot virus. In: Kumer J, Chaube HS, Singh US, Mukhadpadhyay AN (eds) Plant diseases of international importance, vol III. Prentice Hall, New York, pp $335-356$ 
38. Nemeth M (1986) Virus, mycoplasms and rickettsias diseases of fruit trees. Budapest, Hungary

39. Pond SLK, Frost SDW (2005) Not so different after all: a comparison of methods for detecting amino acid sites under selection. Mol Biol Evol 22:1208-1222

40. Sánchez-Navarro JA, Herranz MC, Pallás V (2006) Cell-to-cell movement of Alfalfa mosaic virus can be mediated by the movement proteins of Ilar-, bromo-, cucumo-, tobamo- and comoviruses and does not require virion formation. Virology 346:66-73

41. Sánchez-Navarro JA, Bol JF (2001) Role of the Alfalfa mosaic virus movement protein and coat protein in virus transport. Mol Plant-Microbe Interact 14:1051-1062

42. Sánchez-Navarro JA, Pallás V (1997) Evolutionary relationships in the ilarviruses: nucleotide sequence of Prunus necrotic ringspot virus RNA 3. Arch Virol 142:749-763

43. Sánchez-Navarro JA, Reusken CBEM, Bol JF, Pallás V (1997) Replication of alfalfa mosaic virus RNA 3 with movement and coat protein genes replaced by corresponding genes of Prunus necrotic ringspot ilarvirus. J Gen Virol 78:3171-3176

44. Schmidt HA, Strimmer K, Vingron M, von Haeseler A (2002) TREE-PUZZLE: maximum likelihood phylogenetic analysis using quartets and parallel computing. Bioinformatics 18:502504

45. Schoumacher F, Giovane C, Maira M, Poirson A, Godefroy CT, Berna A (1994) Mapping of the RNA-binding domain of the alfalfa mosaic virus movement protein. J Gen Virol 75:31993202

46. Scott SW, Zimmerman MT, Ge X, MacKenzie DJ (1998) The coat proteins and putative movement proteins of isolates of Prunus necrotic ringspot virus from different host species and geographic origins are extensively conserved. Eur J Plant Pathol 104:155-161

47. Spiegel S, Tam Y, Maslenin L, Kolber M, Nemeth M, Rosner A (1999) Typing Prunus necrotic ringspot virus isolates by serology and restriction endonuclease analysis of PCR products. Ann Appl Biol 135:395-400

48. Vasková D, Petrzik K, Karesova R (2000) Variability and molecular typing of the woody-tree infecting Prunus necrotic ringspot ilarvirus. Arch Virol 145:699-709

49. Xia X, Xie Z (2001) DAMBE: software package for data analysis in molecular biology and evolution. J Hered 92:371-373 